\title{
TELAS ANTIMICROBIANAS IMPREGNADAS CON PARTICULAS DE Ag O Zn RECICLADO INCLUIDAS EN MATRICES SILÍCEAS MODIFICADAS Igal Katerine
}

\author{
Vázquez Patricia (Dir.), Sambeth Jorge (Codir.)
}

Centro de Investigación y Desarrollo en Ciencias Aplicadas (CINDECA), Facultad de Ciencias Exactas, UNLP -CONICET-CIC. katerineigal@gmail.com

PALABRAS CLAVE: Telas antimicrobianas, Sílice, Método sol-gel.

Las mega-ciudades son los sistemas más complejos creados por el hombre. El hábitat urbano y el medioambiente son fuertemente influenciados por los productos ""sintetizados"" y utilizados por los habitantes y estos denominados residuos, tanto industriales como hogareños, terminan en la zona de influencia del mismo asentamiento (ciudad). Esto hace que por mecanismos de contacto directo o de lixiviado algunos elementos contenidos en ellos pasen a formar parte del terreno afectando las áreas cercanas, o puedan difundir hasta los acuíferos pudiendo afectar regiones ubicadas a grandes distancias, degradando la calidad del agua y del suelo que entra en contacto con estos contaminantes.

En Argentina, las pilas y baterías son enviadas con los residuos domiciliarios a los rellenos sanitarios, no existe hasta el momento legislación alguna relativa específicamente al reciclado o disposición final de pilas y baterías, aunque si hay registro de numerosos proyectos de ley al respecto esperando ser tratados (HCDN Trabajo Especial no204, 2012). Una forma muy efectiva de prevenir esta situación es dirigir estos materiales de desecho hacia su reutilización, como ejemplo, podemos citar la reutilización de los materiales que contiene las pilas, tanto la cubierta externa (Zn reciclado) como parte de su relleno interno (carbón mezclado con otros óxidos).
Uno de los desafíos ambientales en la actualidad es el del control microbiológico en ambientes cerrados. Según datos bibliográficos los microorganismos que logran desarrollarse formando biopelículas en sustratos situados en el interior de edificios y viviendas contribuyen a la formación de bioaerosoles al diseminarse parcial o totalmente transportados por el aire. La presencia de éstos agentes contaminantes representan un serio riesgo para la salud humana, en especial en hospitales y centros sanitarios donde las infecciones contraídas son una de las principales causas de muerte.

Por lo tanto es de vital importancia contribuir en la prevención y/o limitación de la proliferación microbiológica en especial en los ambientes cerrados. En tal sentido es fundamental la evaluación de nuevos agentes antimicrobianos que puedan ser aplicados en diversas áreas de desarrollo de materiales como recubrimientos protectores en hospitales, sabanas, guardapolvos de médicos y tantos otros textiles que se encuentran en las salas donde se produce el cruce de diferentes microbios.

Este trabajo de tesis está enfocado a la preparación de nuevos materiales que pueden proporcionar soluciones al control de enfermedades y deterioro de materiales producido por hongos y bacterias, se sintetizaron sílices modificadas con inclusión de Ag y ZnO extraído de pilas en desuso y posteriormente recicladas, a través del método sol-gel, para luego ser impregnadas en telas con el metódo pad-dry-cure obteniéndose telas antimicrobianas.

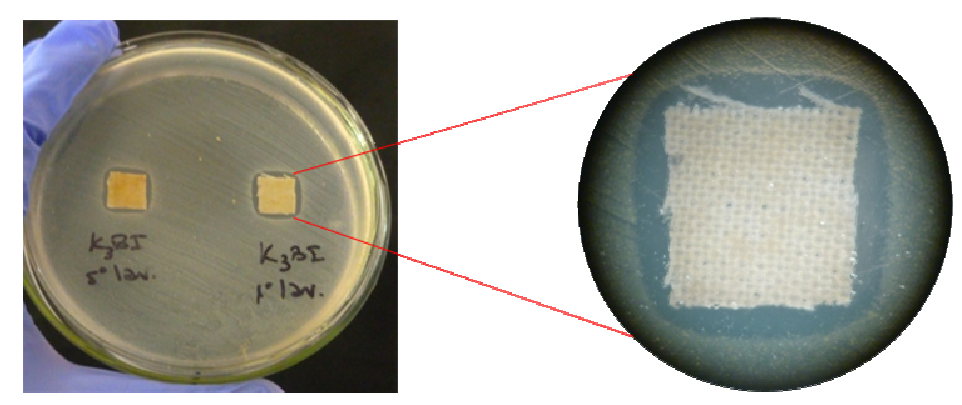

\section{Ensayo antibacteriano de Telas impregnadas con el método pad-dry-cure contra S. aeureus}

